\title{
Assessment of the Effects of Crude Metabolic Extracts (Leaf and Twig) of Loranthus Micranthus
} on Streptozotocin Induced Diabetic Rats

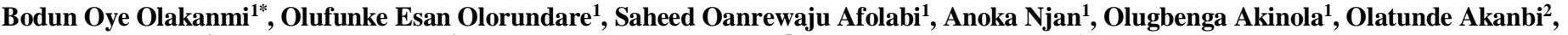
Amase Nyamngee ${ }^{3}$, Adejuwon Adeneye ${ }^{4}$, Ezekiel Olugbenga Iwalewa ${ }^{5}$, James Mukasa. Ntambi ${ }^{6}$

${ }^{1}$ Department of Pharmacology and Therapeutics, College of Health Sciences, University of Ilorin, Ilorin, Nigeria

${ }^{2}$ Department of Veterinary Pathology, Faculty of Veterinary Medicine, University of Ilorin, Nigeria.

${ }^{3}$ Department of Medical Microbiology and Parasitology, Faculty of Basic Medical Sciences, College of Health Sciences, University of Ilorin, Ilorin, Nigeria.

${ }^{4}$ Department of Pharmacology, Faculty of Basic Medical Sciences, College of Medicine, Lagos State University, Lagos, Nigeria.

${ }^{5}$ Department of Pharmacology and Therapeutics, Faculty of Basic Medical Sciences, College of Medicine, University of Ibadan, Nigeria.

${ }^{6}$ Departments of Biochemistry and Nutritional Sciences, University of Wisconsin-Madison, WI, USA.

*Corresponding Author: Bodun Oye Olakanmi, Department of Pharmacology and Therapeutics, College of Health Sciences, University of Ilorin, Ilorin, Nigeria.

Received date: November 01, 2019; Accepted date: December 30, 2019; Published date: January 05, 2020

Citation: Olakanmi Bodun O, Olorundare Olufunke E, Afolabi Olanrewaju O, Anoka N, Olugbenga A, Akanbi Olatunde A. (2020) Assessment of the Effects of Crude Methanolic Extracts (Leaf and Twig) of Loranthus micranthus on Streptozotocin Induced Diabetic Rats,J Diabetes and Islet Biology 2(1); Doi:10.31579/ 2641-8975/015

Copyright: () 2020 Bodun Oye Olakanmi, This is an open access article distributed under the Creative Commons Attribution License, which permits unrestricted use, distribution, and reproduction in any medium, provided the original work is properly cited.

\section{Abstract}

The antidiabetic effects of crude methanolic extracts of the leaf and twig of Loranthus micranthus was evaluated in Wister rats. To assess this, data were obtained for the determinant parameters of diabetic complications.

Streptozotocin was administered for induction of diabetes; diabetic state was confirmed by persistent hyperglycemia (FBG $\geq 300 \mathrm{mg} / \mathrm{dl}$ ) at 72 hours post induction. Invitro inhibitory activity on $\alpha$ - amylase and $\alpha$-glucosidase was assayed. Serum insulin, TNF- $\alpha$, Total cholesterol, HDL, LDL, TG, atherogenic index, liver glycogen and glycated haemoglobin were evaluated. Histology of the pancreas was assessed.

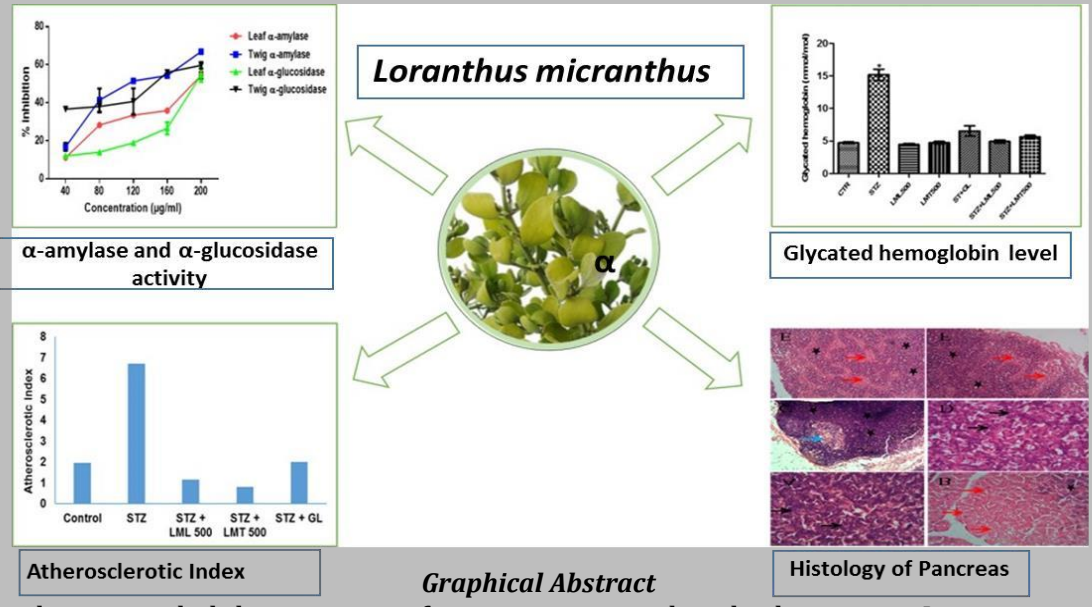

Phytochemical analysis revealed the presence of unique compounds in both extracts. In-vitro assay showed inhibitory effects of both extracts on $\alpha$-amylase and $\alpha$-glucosidase activity. Hyperglycemia was controlled in both extract-treated groups comparable to glibenclamide. Weight loss after diabetic induction was ameliorated in extracts treated groups; serum insulin level of the extracts-treated and glibenclamide treatedgroup were higher than the diabetic control group. Serum TNF- $\alpha$ level of extracts-treated and glibenclamide-treated groups were significantly lower than the diabetic control group. Glycated haemoglobin levels of diabetic control group were higher than the extracts treated and glibenclamide group. Dyslipidemia observed in the diabetic control group were ameliorated in all extract-treated groups; atherogenic index of diabetic control group was higher than extracts-and-glibenclamide treated groups. Histopathological assessment showed that the leaf and twig extracts of Loranthus micranthus may possess $\beta$ cell regenerating activity. Findings from this study suggest that the leaf and twig extracts of Loranthus micranthus ameliorate symptoms and complications of streptozotocin-induced diabetes in rats.

Keywords: Loranthus micranthus, GC-MS, hyperglycemia, atherogenic index, pancreas, glycated-hemoglobin 


\section{Introduction}

Diabetes mellitus (DM) is a group of metabolic diseases characterized byhigh blood sugarlevels over a prolonged period (persistent hyperglycemia), due to defects in secretion of insulin or biologic action of insulin [1,2]. Prolonged diabetes causes many complications, which can be acute or chronic complications. These has been linked to severe dysfunction and damage of various body organs: the eyes, kidneys, nerves, heart, blood vessels; and results annually in more than 5\% deaths worldwide [3,1]. Persistent hyperglycemia has been reported to lead to the generation of free radicals through the formation of Schiff base and amadori products, which are implicated in the end organ damage caused by diabetes mellitus [4].

In 2017, it was estimated that 451 million (age 18-99 years) are living with diabetes worldwide [5]. These figures were expected to increase to 693 million by 2045 [5]. Approximately 5 million deaths worldwide were attributable to diabetes in 2017 within 20-99 years age range [6, 7]. The global healthcare expenditure on people with diabetes was estimated to be USD 850 billion in 2017 [8]. These new estimates of diabetes prevalence, deaths and healthcare expenditure present a large social, financial and health system burden across the world [5].

Diabetic patients with raised plasma glucose levels have proportionally more glycation occurring both intracellularly and extracellularly thereby necessitating the need to treat these complications as an integral part of the clinical stratification of diabetic patients $[9,10]$. Previous studies suggested that inhibition of the production of advanced glycated end products (AGEs) or blockade of their downstream signaling pathway to be promising targets for treatment of patients with diabetic complications $[10,11,12,13]$

One important complication of diabetes is the elevation of atherogenic risk, as diabetic dyslipidemia is a prominent contributor for the development of cardiovascular diseases [14]. Components of the immune system are altered in obesity and accompanying T2D, with striking changes occurring in the adipose tissue, liver, pancreatic islets, the vasculature and circulating leukocytes. These immunological changes include altered levels of specific cytokines and chemokines, changes in the number and activation state of various leukocyte populations, increased apoptosis and tissue fibrosis. Together, these changes suggest that inflammation participates in the pathogenesis of T2D $[15,16]$.

Conventional antidiabetic drugs are both costly and associated with many adverse effects [17]. Thus, the search for safer and affordable antidiabetic drugs has led to studies investigating several plants for such activity. Among plants with potent antidiabetic principles is the hemi parasite, Loranthus micranthus (L. micranthus) which is one of the species of African mistletoe found in Nigeria [18]. Mistletoe species show varying phytochemical components and bioactivity which is dependent on the host plant. The influence of the host tree on the antidiabetic activity has been reported by a group of researchers $[18,19]$. Studies have also shown seasonal variations in the antidiabetic activity of this semi parasite [20,21].African mistletoe parasitic on different host trees has been used for various medicinal purposes and ethnomedically as antidiabetic, antihypertensive and antimicrobial agent [22].

The aim of the present study is to evaluate the effect of crude methanolic extracts of leaf and twig of Loranthus micranthus separately, for their antidiabetic activities and their potentials in ameliorating some parameters of diabetic complications.

\section{Materials and Methods}

\subsection{Plant Materials}

Fresh leaves and twigs of African mistletoe, Loranthus micranthus, were harvested during the dry season at Egbo Area in Ilaro, Ogun State, Nigeria. Plant identification was done at the Department of Plant Biology, University of Ilorin, Ilorin, Nigeria. A specimen was deposited at the herbarium and voucher number UILH/001/1260 was allocated to the sample. Plants materials were dried under the shade, at room temperature for 10days. The dried plants were separated into leaves and twigs and separately pulverized using mortar and pestle and weighed. The resulting powder was macerated in $95 \%$ methanol for 72 hours.

\subsection{Chemicals}

Streptozotocin (STZ) (Sigma Aldrich, USA), p-nitrophenyl $-\alpha-\mathrm{d}$ gluco-pyranoside, p-nitrophenyl - $\beta$-d - glucopyranoside, $\alpha$ - glucosidase, $\alpha$ - amylase, carboxy methyl cellulose (Elabscience, UK), Elisa Rat insulin kit Elabscience, UK, Elisa Rat glycated hemoglobin kit, Elabscience, UK, Elisa Rat TNF- $\alpha$ kit, Elabscience, UK, HDL-Cholesterol Assay kit, Elabscience, UK, Cholesterol CHOD-PAP Assay kit, Elabscience, UK, Triglyceride GPO-PAP Assay kit, Elabscience, UK, Glycogen Assay kit (Sigma-

Aldrich), USA, Glibenclamide 5mg (Daonil), Aventis Pharma Ltd, Glucose, PBS, citrate buffer.

\subsection{Preparation of Extracts}

Cold maceration was used for the extraction, in which $1 \mathrm{~kg}$ each of ground dried leaves and twigs were soaked in 3.5liters of 95\% aqueous methanol. The set up was intermittently shaken vigorously for 72 hours. The (residue) was removed by clarification using muslin which was discarded, and later filtered through Whatman No1 filter paper. The filtrates were then dried in-vacuo using a rotary evaporator at $40^{\circ} \mathrm{C}$. The resultant semisolid was then concentrated on a water bath shaker at $40^{\circ} \mathrm{C}$ for $60 \mathrm{hrs}$.

\subsection{Gas Chromatography Mass Spectrometer (GC-MS)}

\subsubsection{Gas Chromatography (GC) Analysis}

Gas Chromatography (GC) analyses were performed on an Orion micromat 412 double focusing gas chromatography system fitted with two capillary columns coated with Cp-Sil 5 and Cp-Sil 9 (fused silica, $25 \mu \mathrm{m} \times 0.25 \mathrm{~mm}, 0.15 \mu \mathrm{m}$ film thickness) and flame ionization detector (FID). The volume of material injected was $0.2 \mathrm{~mL}$, and the split ratio was $1: 30$. Oven temperature was programmed from $50-230^{\circ} \mathrm{C}$ at $3^{\circ} \mathrm{C} / \mathrm{min}$ using helium as a carrier gas. Injection and detector temperature were maintained at $200{ }^{\circ} \mathrm{C}$ and $250{ }^{\circ} \mathrm{C}$, respectively. Qualitative data were obtained by electronic integration of FID area percent without the use of correction factors.

\subsubsection{Mass Spectrometry (MS) Analysis}

In MS analysis, a Hewlett - Packed HP 5890A GC, interfaced with a VG analytical 70-250s double focusing mass spectrometer were used. Helium was used as the carrier gas at $1.2 \mathrm{ml} / \mathrm{min}$. The MS operating conditions were: ionization voltage $70 \mathrm{ev}$, ion source $230^{\circ} \mathrm{C}$. The $\mathrm{GC}$ was fitted with a $25 \mathrm{~m} \times 0.25 \mathrm{~mm}$, fused silica capillary column coated with $\mathrm{Cp}-$ Sil 5 . The film thickness was $0.15 \mu \mathrm{m}$; the GC operating conditions were identical with those of GC analyses. The MS data were acquired and processed by on-line desktop with a computer equipped with disk memory. The percentage compositions of the compounds were computed in each case of retention indices (determined relative to the retention times 
of series of n-alkanes) and mass Spectra with those of authentic samples and with data from literature [23,24].

\subsection{Acute toxicity study}

Twenty-four female Wistar rats divided into four groups receiving $L$. micranthus twig and leaf extracts at doses of 100, 250, 500 and $1000 \mathrm{mg} / \mathrm{kg}$ daily for a period of 2 weeks. Each group consisted of three rats for each dose employed. The animals were observed during the first hour continuously and then every hour for six hours, thereafter at 12 hours and 24 hours. Animals were then observed every 24 hours for 2 weeks for any physical signs of toxicity such as writhing, gasping, palpitation and decreased respiratory rate or mortality.

\subsection{Experimental Animals}

Fifty-five (55) female rats, about 8 weeks old, weighing between 100$120 \mathrm{~g}$ were used for the study. Animals were housed in Animal House Facility in the Central Research Laboratory, University of Ilorin, Ilorin, Nigeria, for 7 days under standard conditions of appropriate ventilation, temperature of $22-25^{\circ} \mathrm{C}$, relative humidity of $50 \%$ and 12 hours day and night cycle. Animals were fed with standard rat chow and water was supplied ad libitum throughout the acclimatization period. Stressful conditions were avoided all through the experimental period.

\subsection{Induction of Diabetes}

Diabetes was induced in 40 rats by an intraperitoneal injection of a fresh solution of a single dose of streptozocin (STZ) Sigma Aldrich Chemicals, USA. The solution was prepared by dissolving STZ in $0.1 \mathrm{M}$ sodium citrate buffer, $\mathrm{pH} 4.5$. Animals were administered with a dose of $65 \mathrm{mg} / \mathrm{kg}$ body weight after been fasted overnight, according to the method described by Lenzen, 2008 [25]. Immediately after diabetic induction, animals were given $50 \%$ glucose solution in their drinking water ad libitum. Animals with fasting blood Glucose level (FBG) between $340-$ $600 \mathrm{mg} / \mathrm{dl}$ after $72 \mathrm{hrs}$ were considered diabetic and selected for the diabetic groups. For the purpose of treatment, the rats were randomly divided into the following experimental groups:

\subsection{Experimental Groups}

Group 1 = Normal control $(\mathrm{n}=5)$

Group $2=$ Normal rats $+500 \mathrm{mg} / \mathrm{kg}$ leaf extract $(\mathrm{n}=5)$

Group $3=$ Normal rats $+500 \mathrm{mg} / \mathrm{kg}$ twig extract $(\mathrm{n}=5)$

Group $4=$ Diabetic rats $+500 \mathrm{mg} / \mathrm{kg}$ leaf extract $(\mathrm{n}=5)$

Group 5 = Diabetic rats $+500 \mathrm{mg} / \mathrm{kg}$ twig extract $(\mathrm{n}=5)$

Group $6=$ Diabetic rats + Distilled water $(n=5)$

Group $7=$ Diabetic rats $+5 \mathrm{mg} / \mathrm{kg}$ glibenclamide $(\mathrm{n}=5)$

Group $8=$ Diabetic rats $+250 \mathrm{mg} / \mathrm{kg}$ leaf extract $(\mathrm{n}=5)$

Group $9=$ Diabetic rats $+250 \mathrm{mg} / \mathrm{kg}$ twig extract $(\mathrm{n}=5)$

Group $10=$ Diabetic rats $+125 \mathrm{mg} / \mathrm{kg}$ leaf extract $(\mathrm{n}=5)$

Group $11=$ Diabetic rats $+125 \mathrm{mg} / \mathrm{kg}$ twig extract $(\mathrm{n}=5)$

\subsection{Body Weight Evaluation}

Weights of the experimental animals were obtained at the beginning of the study- day 0 , day 7 , day 10 and day 14 of the experiment. Weights obtained were analyzed statistically.

\subsection{Plasma Glucose Level}

Plasma glucose level was determined by Accucheck plus GCT Glucometer (Roche, USA). The monitor of the glucometer device uses a reflectance photometer for measuring the intensity of the color formed at the end of the reaction. This measurement uses software which translated the intensity to the corresponding glucose values. The fasting blood glucose (FBG) of all animals was measured at day zero before diabetic induction to obtain baseline glucose level for all the rats; and thereafter, following the induction of diabetes and throughout the treatment period. Plasma glucose was determined 72hours after STZ injection for confirmation of diabetes. In addition, blood glucose was measured weekly for a period of 2 weeks using the glucometer method discussed earlier, following which the animals were sacrificed.

\subsection{Oral Glucose Tolerance Test}

Blood Glucose level of 16 hours fasted rats was determined, and the value used as zero time of the test. At the end of the experiment, i.e. after the last dose of the vehicle, or glibenclamide or extracts, glucose solution $(50 \%)$ at a dose of $2 \mathrm{~g} / \mathrm{kg}$ was given by oral intubation, according to the methods described by Ayala et al., (2010) [26]. Blood samples were taken at 30, 60, 90 and 120 minutes after glucose loading and blood glucose level determined with one touch glucometer (Accucheck Plus GCT, Glucometer). Plots of the values of blood glucose level (mg/dL) versus the time intervals (min) were constructed and the area under the curve (AUC) calculated using the Trapezoidal method. The AUCs foreach group was compared and tested for significance against the diabeticuntreated group and this represented the tissue glucose utilization.

\subsection{In-Vitro Antidiabetic Assays}

\subsection{1. $\alpha$ - Amylase Inhibitory Activity Assay}

The effect of crude methanolic extracts of $L$. micranthus (leaf and twig) on $\alpha$ - amylase activity was determined by the method described by Ali et al., 2006 [27]. Briefly, $50 \mu 1$ of $\alpha$ - amylase $(5 \mathrm{U} / \mathrm{ml})$ was pre-incubated for $20 \mathrm{~min}$ with $50 \mu \mathrm{l}$ aliquots of extracts. The reaction was started by the addition of $50 \mu \mathrm{l}$ starch $(0.5 \%)$ dissolved in $20 \mathrm{mM}$ phosphate buffer at $\mathrm{pH}$ 6.9. The reaction mixture was incubated for a further $20 \mathrm{~min}$ at $37^{\circ} \mathrm{C}$ and the catalytic reaction terminated by addition of $2.0 \mathrm{ml}$ of DNS reagent (1\% 3, 5-dinitrosalicicyclic acid (DNS) and 12\% sodium potassium tartrate in $0.4 \mathrm{M} \mathrm{NaOH}$ ). The reaction mixture was heated for $15 \mathrm{~min}$ at $100^{\circ} \mathrm{C}$. $\alpha$-amylase activity was determined by spectrophotometric measurement of the absorbance at $540 \mathrm{~nm}$. Percentage $\alpha$-amylase inhibition was calculated according to the following formula;

$\left(A_{0}-A_{1}\right) / A_{0} \times 100$ where, A0 was the absorbance of the control (blank, without extract) and $A_{1}$ was the absorbance in the presence of the extract.

\subsection{2. $\alpha$ - Glucosidase Inhibitory Activity}

The inhibitory effect of $L$. micranthus extracts on $\alpha$-glucosidase activity was determined according to the chromogenic method described by Kim et al. (2005) [28]. Briefly, $\alpha$-glucosidase (5 units) was pre-incubated with $20 \mu \mathrm{g} / \mathrm{ml}$ of the different extracts for $15 \mathrm{~min}$. Paranitrophenylglucopyranoside (PNPG) $(3 \mathrm{mM})$ dissolved in $20 \mathrm{mM}$ phosphate buffer, $\mathrm{pH} 6.9$, was added to start the reaction. The reaction mixture was further incubated at $37^{\circ} \mathrm{C}$ for $20 \mathrm{~min}$ and stopped by addition of $2 \mathrm{ml}$ of $0.1 \mathrm{M} \mathrm{Na}_{2} \mathrm{CO}_{3}$. Using a spectrophotometer, the $\alpha$-glucosidase 
activity was determined by measuring the yellow colored p-nitrophenol released from PNPG at $400 \mathrm{~nm}$. Percentage $\alpha$-glucosidase inhibition was calculated according to the following;

$\left(\mathrm{A}_{0}-\mathrm{A}_{1}\right) / \mathrm{A} 0 \times 100$ where, $\mathrm{A}_{0}$ was the absorbance of the control (blank, without extract) and $A_{1}$ was the absorbance in the present extract.

\subsection{Sample Collection and Handling}

At the end of the 14-day treatment blood samples were drawn 3 hours after the last dose from the orbital sinus of rats, under light ether anesthesia into two different tubes (heparin and plain bottles) for each animal respectively. The samples were immediately centrifuged at $0^{\circ} \mathrm{C} / 1000 \mathrm{~g}$ for $15 \mathrm{~min}$ for separation of serum. The resulting serum samples was separated and kept at $-20^{\circ} \mathrm{C}$ until used for required analysis.

\subsection{Estimation of Plasma Insulin Level}

Insulin concentration was determined by radioimmunoassay procedure using a Rat INS (Insulin) ELISA Kit (Elabscience, E-EL-R2466, 96T). This assay has a high specificity as it recognizes natural and recombinant Rat INS without significant cross-reactivity or interference between Rat INS and analogues. The ELISA kit uses Sandwich-ELISA as the method. Sample and reagent preparation was done according to the manufacturer's manual using serum samples. Spectrophotometric measurements were done at a wavelength of $450 \mathrm{~nm} \pm 2 \mathrm{~nm}$. Concentration of insulin in the samples was calculated by comparing the OD of the samples to the standard the curve.

\subsection{Estimation of Tissue Glycogen}

At the end of the experiments, livers collected were weighed and divided into 2 sample tubes, for liver glycogen assay and histopathological evaluation. Liver samples for glycogen assay were immediately frozen in phosphate buffered saline prior to the assay. Glycogen content of liver was assayed using glycogen assay kit (Sigma-Aldrich, 3050 Spruce Street, ST. Louis, MO 63103 USA). The coupled enzyme assay produces a colorimetric $(570 \mathrm{~nm})$ product, proportional to the glycogen concentration present in the samples.

\subsection{Estimation of Plasma Lipid Profile}

Blood lipid (TC, HDL and TG) levels were determined using spectrophotometric assay techniques. Assays were conducted according to the manufacturer's manual. Serums of all the animals in different groups were analyzed.

\subsubsection{Total Cholesterol}

Total cholesterol in serum was assayed using Elabscience Total Cholesterol Assay Kit. The assay is based on the enzyme driven reaction that quantifies both cholesterol esters and free cholesterol. Cholesterol esters were hydrolyzed via cholesterol esterase to cholesterol, which was subsequently oxidized by cholesterol oxidase to the ketone cholest-4-en3 -one and hydrogen peroxide. Hydrogen peroxide was detected with a high specificity colorimetric probe. Horseradish peroxidase (HRP) catalyzes the reaction between the probe and hydrogen peroxide, which was bound in a 1:1 ratio. Samples were compared to a known concentration of cholesterol standard in a 96-well microtiter plate. Samples and standards were incubated for 45 mins and then read on a standard 96-well colorimetric plate reader, at absorbance of $540 \mathrm{~nm}$. The concentration of cholesterol in each sample was calculated by comparing the sample absorbance values to the cholesterol standard curve.
Samplecorrected absorbance
Total Cholesterol $(\mu \mathrm{M})=$
Slope x Sample dilution

\subsubsection{Serum Triglycerides Concentration}

Triglycerides level in serum was assayed using GPO-PAP method (Elabscience TG Assay Kit).All reagents were ready to use and were mixed according to the manufacturer's manual. The mixture was measured after incubating at $37^{\circ} \mathrm{C}$ for $5 \mathrm{~min}$. Absorbance of sample against reagent blank was read at 550nm within $60 \mathrm{~min}$. Triglycerides concentration in the sample was calculated as follows:

A sampleX concentration of Standard = Triglycerides concentration A Stand

(where $\mathrm{A}_{\text {sample }}$ and $\mathrm{A}_{\text {standard: }}$ absorbance of sample and standard respectively)

\subsubsection{High Density Lipoprotein Cholesterol (HDL-C) Assay}

High Density Lipoprotein Cholesterol (HDL-C) in the serum of each sample was assayed according to the manufacturer's manual using direct method, with Elabscience High Density Lipoprotein Cholesterol (HDL-

C) assay kit. $10 \mu \mathrm{l}$ of serum was mixed with reagents $R_{1}$ and $R_{2}$. The solutions were mixed thoroughly and incubated at $37^{\circ} \mathrm{C}$ for 5 minutes. The absorbance was read at 546nm wavelength. HDL Cholesterol concentration in the samples was calculated according to the calculation formula in the manual.

(Absorbance of sample-Blank)

$\mathrm{X}$ concentration of standard $=$

HDL-C concentration

(Absorbance of standard - Blank)

\subsubsection{LDL Cholesterol}

LDL-Cholesterol was estimated by using the formula of Friedewald et al., 1972 [29]:

LDL - Cholesterol $=$ Total cholesterol - HDL-Cholesterol - TG/5.

2.15.5. Atherogenic Index: The Atherogenic index (AI) was calculated according to the formula of Harnafiet al., 2014 [30].

$$
\mathrm{AI}=\text { Total Cholesterol }- \text { HDL-Cholesterol }
$$

\section{HDL - Cholesterol}

\subsection{Glycated Hemoglobin (HbA1c)}

Glycated hemoglobin was assayed from the whole blood usingHbA1c ELISA kit (Elabscience) which employed the competitive enzyme immunoassay technique, utilizing a monoclonal anti-HbAlc antibody and an $\mathrm{HbA1c-HRP}$ conjugate. The intensity of color formed was measured spectrophotometrically at $450 \mathrm{~nm}$ on a microplate reader. The intensity of the color was inversely proportional to the HbAlc concentration. A standard curve was plotted relating the intensity of the color (O.D.) to the concentration of standards. The HbA1c concentration in each sample was determined from this standard curve.

\subsection{Tumor Necrotic Factor-A (TNF- $\alpha)$}


TNF- $\alpha$ was assayed using rat TNF- $\alpha$ ELISA Kit (Elabscience, E-ELR0019).Standards and samples were prepared according to the manufacturer's specification. The prepared solutions were added to the appropriate micro ELISA plate wells and combined with specific antibody for TNF- $\alpha$ and Avidin-Horseradish Peroxidase (HRP) conjugate and were incubated. The free unbound components were washed away. Only the wells that contained TNF- $\alpha$, biotinylated detection antibody and Avidin-HRP conjugate appeared blue. The enzyme-substrate reaction was terminated by addition of $\mathrm{H}_{2} \mathrm{SO}_{4}$ which turned the blue colour yellow. The optical density (OD) was measured spectrophotometrically at a wavelength of $450 \mathrm{~nm}$. The OD values obtained were proportional to the concentration of TNF- $\alpha$ in each microplate well. The concentration of TNF- $\alpha$ in the samples was calculated by comparing the OD of samples was determined from the standard curve.

\subsection{Histopathology}

Pancreas and pancreatic tissues within the duodenal loop of each rat in all groups were taken out immediately after animalswere sacrificed, at the termination of the experiments. These were fixed in $10 \%$ phosphate buffered formaldehyde solution for at least 48 hours. The tissues were later cut into $0.5 \times 1 \mathrm{~cm}$ in diameter each using scalpel blade and processed using an automatic tissue processor. Processed tissues were embedded using MP3 tissue embedding center. A rotary microtome machine was used to section at $5 \mu \mathrm{m}$. Hematoxylin and eosin (H\&E) stain was used for staining sections which were mounted using dextrin plasticizer xylene (DPX). For histopathological examination, low and high powered field of Carl Zeiss ${ }^{\circledR}$ binocular microscope was used.

\subsection{Statistical Analysis}

Data obtained in the present study were subjected to statistical analysis using GraphPad Prism application version 6. The means, standard errors of means and standard deviations were obtained as summary statistics. The obtained summary statistics were subjected to one-way analysis of variance (ANOVA) using the Tukey's post-hoc test to check for significant relationship between experimental groups. The data were pictorially presented as line graphs and bar charts with bars and error bars representing the means and standard errors of means respectively. Statistical significance was set at $\mathrm{p}$ value less than 0.05 .

\section{Results}

\subsection{Phytochemical Analysis}

Qualitatively, 48 and 40 compounds were found to be prominent in leaf and twig extract of $L$. micranthus respectively. Thirteen of the compounds were commonly found in both leaf and twig of L. micranthus. The similar compounds are Cyclobutanol, 1,4- Dimethyl hexyl alanine, Piperazine, 4Butyl phenol, N-(2-Hydroxy benzyl) alanine, Palmitic acid methyl ester, Ethyl hexadecanoate, 2- Undecyl phenol, Phytol, Methyl stearate, Methyl linoleate, Ethyl oleate and Squalene.

Quantitatively, Palmitic acid methyl ester, Phytol, Methyl stearate and Methyl linoleate were found in higher quantity in the leaf than the twig extracts of L. micranthus. However, Cyclobutanol, 1,4- Dimethyl hexyl alanine, Piperazine, 4-Butyl phenol, N-(2-Hydroxy benzyl) alanine, Ethyl hexadecanoate, 2- Undecyl phenol, Ethyl oleate and Squalene were found in significant amounts in the twig compared to the leaf extract of African Mistletoe.

\subsection{Mean Body Weight}

\begin{tabular}{|c|c|c|c|}
\hline $\begin{array}{c}\text { (\%)Mass Spectra } \\
\text { Functional Compounds } \\
\mathrm{S} / \mathrm{N}\end{array}$ & R.I & Composition Data & Group \\
\hline Cyclobutanol & 668 & 2739445770 & $-\mathrm{OH}$ \\
\hline Methoxyoxirane-2- & 827 & $\begin{array}{c}0.32945587387 \\
-\mathrm{COOH}-\end{array}$ & $\begin{array}{c}\mathrm{C}-\mathrm{O}-\mathrm{C} \\
\text { Carboxylic acid }\end{array}$ \\
\hline $\begin{array}{l}\text { Ethyl trans-3-methyl-2- } \\
\text { carboxylate }\end{array}$ & 837 & $\begin{array}{c}0.32729455774 \\
- \text { C-O-C }\end{array}$ & Oxirane \\
\hline $\begin{array}{l}\text { l-Alanine, trimethylsilyl } \\
\text { ester }\end{array}$ & 874 & 44597586103 & $\mathrm{NH}_{2,-} \mathrm{COO}$ \\
\hline Neoheptanol & 875 & 577385101115 & $-\mathrm{OH}$ \\
\hline $\begin{array}{l}\text { Vinyl2,2-dimethyl } \\
\text { Butanoate }\end{array}$ & 889 & 4143577185 & \\
\hline 1,4-Dimethyl hexylamine & 931 & 0.144567097114 & $-\mathrm{NH}_{2}$ \\
\hline Piperazine & 1011 & 2844568385 & $-\mathrm{NH}$ \\
\hline
\end{tabular}




\begin{tabular}{|c|c|c|c|}
\hline Coumaran & 1036 & 637791105120 & $-\mathrm{C}=\mathrm{O},-\mathrm{C}=\mathrm{C}$ \\
\hline -limonene diepoxide & 1128 & 4143678395 & $-\mathrm{C}-\mathrm{O}-\mathrm{C}$ \\
\hline -Campholenal & 1153 & 8193108119137 & $-\mathrm{CHO},-\mathrm{C}=\mathrm{C}$ \\
\hline 2-Propyl malonic acid & 1266 & 4144607387 & $-\mathrm{COOH}$ \\
\hline D-2-Deoxyribose & 1274 & 2731445773 & $-\mathrm{OH},-\mathrm{C}=\mathrm{O}$ \\
\hline P-butyl phenol & 1312 & $7791 \mathbf{1 0 7 1 2 1} 123$ & $\mathrm{OH},-\mathrm{C}=\mathrm{C}$ \\
\hline 2,3-Bis(1,methylallyl) & 1328 & $\begin{array}{c}8297124126150 \\
\text { pyrollidine }\end{array}$ & $-\mathrm{NH}$ \\
\hline 3-Butyl indolizidine & 1393 & 96110124138152 & $-\mathrm{NH}$ \\
\hline P-Coumaric alcohol & 1464 & 94107121131150 & $-\mathrm{OH},-\mathrm{C}=\mathrm{C}$ \\
\hline Methyl alpha-L-fuco & 1471 & 43607487100 & -OH pyranoside \\
\hline $\begin{array}{l}\text { 2,3-Dimethyl- 2(3- } \\
\text { oxobutyl) }\end{array}$ & 1521 & 4143698297 & $-\mathrm{C}=\mathrm{O}$ \\
\hline Trimethyl[1-methyl & 1533 & 7387101117129 & dodecyl)oxy] Silane \\
\hline Methyl isomyristate & 1615 & 577487101115 & $\begin{array}{c}-\mathrm{COO} \\
\text { Cyclohexanone }\end{array}$ \\
\hline $\begin{array}{c}\text { 3-Oxo-alpha-ionol } \\
\text { Methyl 3,4, trimethoxy } \\
\text { Benzoate }\end{array}$ & $\begin{array}{l}1627 \\
1628\end{array}$ & $\begin{array}{r}7995 \mathbf{1 0 8} 123137 \\
155168195196 \mathbf{2 2 6}\end{array}$ & $\begin{aligned}-\mathrm{OH},-\mathrm{C} & =\mathrm{O}-\mathrm{C}=\mathrm{C} \\
\mathrm{C} & =\mathrm{C}\end{aligned}$ \\
\hline Methyl tetradecanoate & 1715 & 4155577487 & $-\mathrm{COO}$ \\
\hline Hexahydrofarnesyl acetone & 1754 & 4143587185 & $-\mathrm{C}=\mathrm{O}$ \\
\hline Sulfurous acid, isohexyl & 1773 & 8385101137167 & Hexyl ester \\
\hline Methyl pentadecanoat & 1779 & 577487101115 & $-\mathrm{COO}$ \\
\hline N-(2-Hydroxybenzyl) & 1803 & 44567795107 & alanine \\
\hline Palmiticacid, methyl ester & 1878 & 577487101115 & $-\mathrm{COO}$ \\
\hline $\begin{array}{c}\text { 3,5,11,15-Tetramethyl-1- } \\
\text { Hexadecen-3-ol }\end{array}$ & 1899 & 577195109123 & $\mathrm{C}=\mathrm{C},-\mathrm{OH}$ \\
\hline Farnesyl acetone & 1902 & 4143698195 & $-\mathrm{C}=\mathrm{O}$ \\
\hline Heptadecanoic acid methyl & 1978 & 577487101115 & -COO ester \\
\hline Ethyl hexadecanoate & 1978 & 577388101115 & $-\mathrm{COO}$ \\
\hline 2-Undecyl phenol & 2008 & 7791107121131 & $-\mathrm{OH},-\mathrm{C}=\mathrm{C}$ \\
\hline Phytol & 2045 & 41577195111 & $-\mathrm{OH}$ \\
\hline Methyl stearate & 2077 & 41437487101 & $-\mathrm{COO}$ \\
\hline Methyl linoleate & 2093 & 4155678195 & $-\mathrm{COO}$ \\
\hline Ethyl oleate & 2185 & 4155698388 & $-\mathrm{COO}$ \\
\hline Methyl-18-methyl nona & 2212 & 577487101115 & $\begin{array}{c}\text {-COO } \\
\text { decanoate }\end{array}$ \\
\hline
\end{tabular}




\begin{tabular}{|c|c|c|c|}
\hline Methyl heneicosanoate & 2375 & $4357 \mathbf{7 4} 87111$ & $-\mathrm{COO}$ \\
\hline Methyl docosanoate & 2475 & $4357 \mathbf{7 4} 87101$ & $-\mathrm{COO}$ \\
\hline Methyl-8, 11, 14-docosa & 2499 & $41 \mathbf{5 5} 678195$ & -COO trienoate \\
\hline Glycerol-2-monooleate & 2705 & $41 \mathbf{5 5} 698195$ & $-\mathrm{COO},-\mathrm{OH}$ \\
\hline Lanosterol & 2882 & $4143 \mathbf{6 9} 8195$ & $-\mathrm{OH}$ \\
\hline Squalene & 2914 & $4143 \mathbf{6 9} 8195$ & $-\mathrm{OH},-\mathrm{C}=\mathrm{C}$ \\
\hline dl- -Tocopherol & 3149 & $121136149 \mathbf{1 6 5} 177$ & $\begin{array}{c}\text { Octa decyl } \\
\text { ester }\end{array}$ \\
\hline Phthalic acid, isobutyl & 3364 & $121133 \mathbf{1 4 9 1 6 7 2 0 5}$ & - \\
\hline TOTAL & $\mathbf{9 4 . 9}$ & & \\
\hline
\end{tabular}

Table 1: Shows the identities, retention indices, percentage composition and mass spectra data of the constituents of methanolic extract of $L$. micranthus. In the Table, 48 compounds were identified from their mass spectra, the number represented $94.9 \%$ of the leaf.

\subsection{Effect of Extracts on Fasting Blood Glucose}
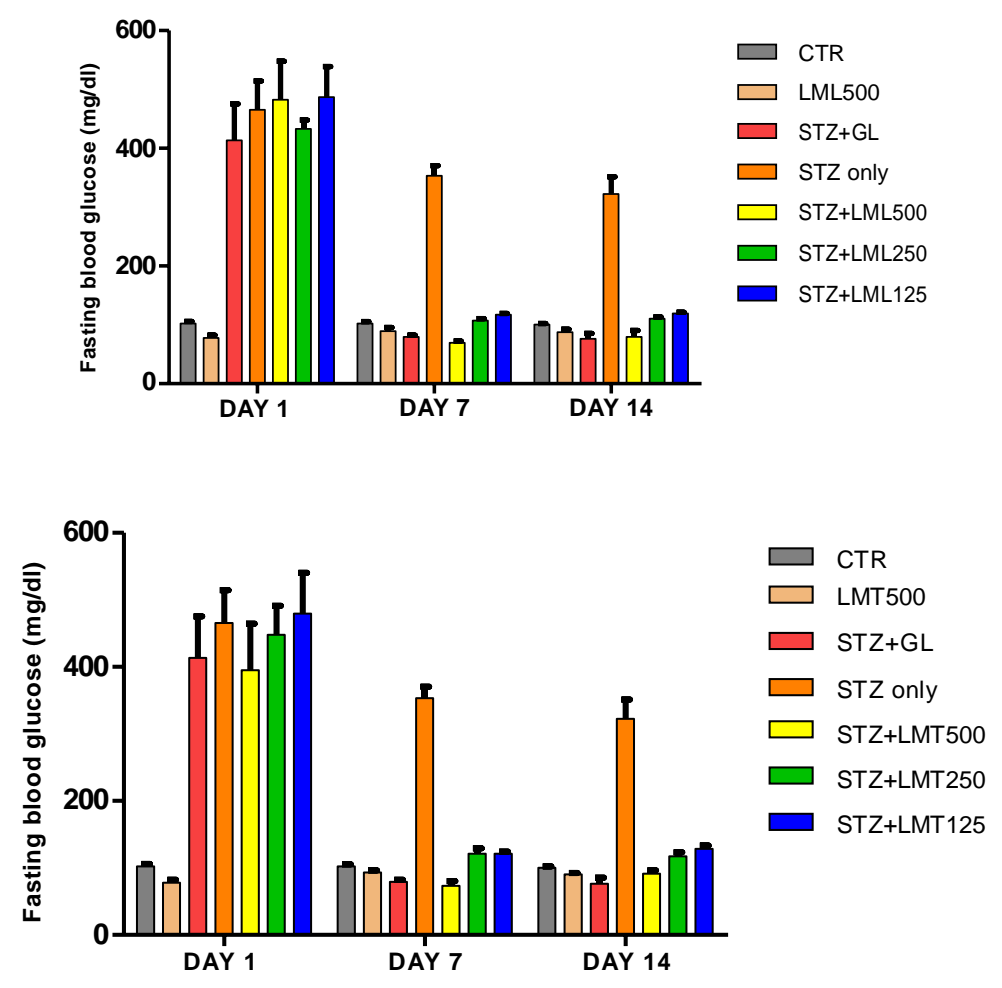

Figure 1: Chart A and B showing the fasting blood sugar of the experimental animals on day 1 (after diabetes induction), day 7 (7 days treatment) and day 14 (14 days treatment) for leaf and twig extract respectively. There was hyperglycemia in all STZ treated groups after diabetic induction. STZ-only group showed persistent hyperglycemia all through the experiment.

Treatment groups (Glibenclamide, LML and LMT extracts) showed adequate glycemic control at all concentrations used. CTR $=$ control, $\mathrm{LML}=$ L. micranthus leaf extract, $\mathrm{LMT}=$ L. micranthus twig extract, $\mathrm{STZ}=$ streptozotocin, $\mathrm{GL}=$ glibenclamide.

\begin{abstract}
* is p value $<0.05$ relative to controlgroup. Data is presented as mean (bars) \pm standard error of mean (error bars).
\end{abstract}

\subsection{Biochemical Parameters}




\subsubsection{In Vitro Assay}

The inhibitory activity of the leaf and twig extract of L. micranthus on $\alpha$-amylase and $\alpha$-glucosidase enzyme activity were evaluated in vitro at different extractconcentrations. The result obtained was analyzed and are presented in the line graphs below.
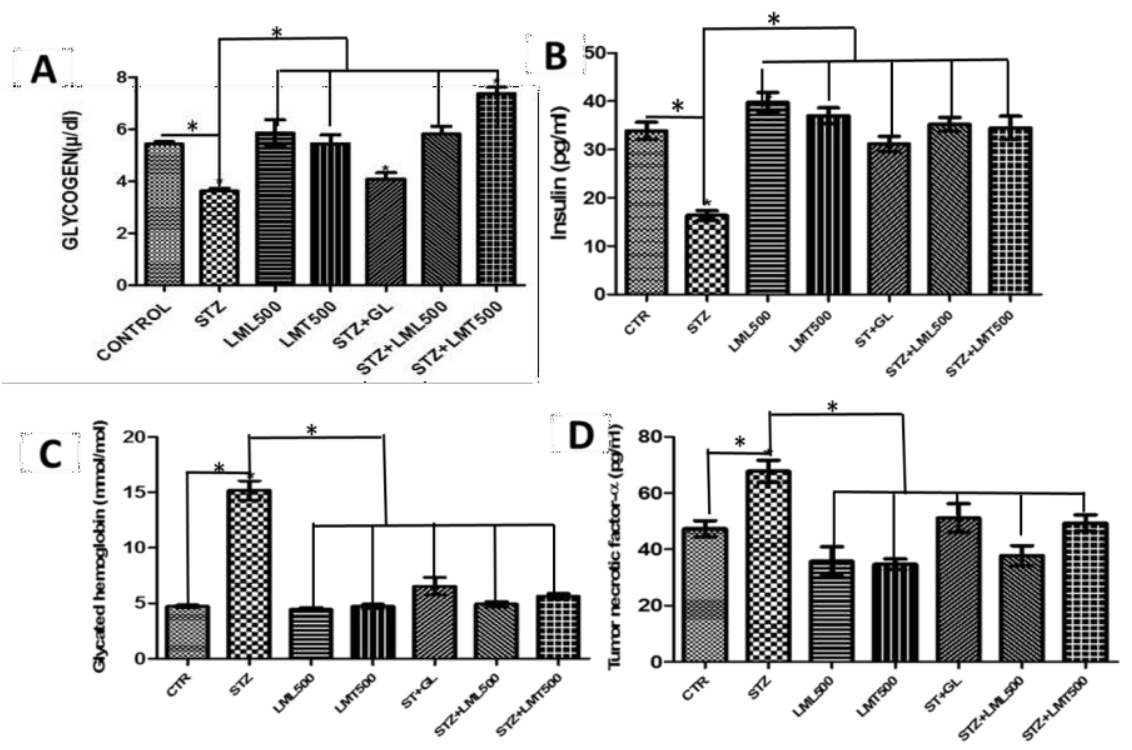

Figure 3: Chart A, B, C and D showing levels of liver glycogen, serum insulin, glycated haemoglobin and tumour necrosis factor- $\alpha$ in the experimental animals of various groups.STZ Only and GL treatment groups showed significantly lower $(\mathrm{p}<0.05)$ liver glycogen le vels compared with LML and LMT treated groups. Insulin level was significantly lower $(\mathrm{p}<0.05)$ in STZ only group compared with all other groups. Glycated hemoglobin was significantly higher $(\mathrm{p}<0.05)$ in STZ only group. Tumor necrotic factor- $\alpha$ was significantly higher $(\mathrm{p}<0.05)$ in $\mathrm{STZ}$ only group.

$\mathrm{CTR}=$ control, $\mathrm{LML}=$ L. micranthusleaf extract, $\mathrm{LMT}=$ L. micranthus twig extract, $\mathrm{STZ}=$ streptozotocin, GL= glibenclamide. Data is presented as mean (bars) \pm standard error of mean (error bars). * is significant level of $\mathrm{p}<0.05$ relative to the STZ group.

\section{LIPID PROFILE}

\begin{tabular}{|c|c|c|c|c|c|}
\hline GROUPS & $\begin{array}{c}\text { Triglycerides } \\
(\mathbf{m g} / \mathbf{d l})\end{array}$ & $\begin{array}{c}\text { Total cholesterol } \\
(\mathbf{m g} / \mathbf{d l})\end{array}$ & $\begin{array}{c}\text { High density } \\
\text { lipoprotein } \\
(\mathbf{m g} / \mathbf{d l})\end{array}$ & $\begin{array}{c}\text { Low density } \\
\text { lipoprotein } \\
(\mathbf{m g} / \mathbf{d l})\end{array}$ & $\begin{array}{c}\text { Atherogenic } \\
\text { index } \\
(\mathbf{m g} / \mathbf{d l})\end{array}$ \\
\hline CONTROL & $176.12 \pm 16.41$ & $102.21 \pm 4.00$ & $35.65 \pm 5.08$ & $30.05 \pm 3.42$ & $1.94 \pm 0.30$ \\
\hline STZ only & $653 \pm 111.08^{*}$ & $216.22 \pm 10.12^{*}$ & $39.34 \pm 7.64$ & $69.41 \pm 11.73^{*}$ & $6.70 \pm 1.08^{*}$ \\
\hline LML500 & $133.00 \pm 6.56^{* \#}$ & $118.23 \pm 3.11$ & $58.56 \pm 3.24^{*}$ & $33.36 \pm 1.17$ & $1.04 \pm 0.07$ \\
\hline LMT500 & $158.00 \pm 27.56^{* \#}$ & $114.00 \pm 9.12$ & $51.12 \pm 5.34^{*}$ & $32.08 \pm 1.84$ & $1.26 \pm 0.11$ \\
\hline STZ+GL & $227.45 \pm 32.41$ & $126.34 \pm 10.13$ & $46.23 \pm 6.00$ & $34.46 \pm 1.72$ & $1.99 \pm 0.20$ \\
\hline STZ+LML500 & $197.11 \pm 8.34$ & $138.23 \pm 8.08^{* \#}$ & $65.44 \pm 5.56^{* \#}$ & $34.32 \pm 1.32$ & $1.14 \pm 0.16$ \\
\hline STZ+LML250 & $191.23 \pm 8.83$ & $141.35 \pm 7.04^{* \#}$ & $55.12 \pm 4.11^{*}$ & $43.00 \pm 2.24^{* \#}$ & $1.43 \pm 0.07$ \\
\hline STZ+LML125 & $151.34 \pm 20.45^{* \#}$ & $159.37 \pm 4.04^{* \#}$ & $58.34 \pm 5.45^{*}$ & $44.00 \pm 3.49^{* \#}$ & $1.65 \pm 0.19$ \\
\hline STZ+LMT500 & $155.43 \pm 20.34^{*}$ & $152.54 \pm 5.67^{* \#}$ & $85.72 \pm 5.44^{* \#}$ & $36.55 \pm 1.24^{*}$ & $0.79 \pm 0.08^{* \#}$ \\
\hline STZ+LMT250 & $166.34 \pm 6.00$ & $129.24 \pm 4.08$ & $52.86 \pm 2.34^{*}$ & $41.75 \pm 2.89^{* \#}$ & $1.44 \pm 0.09$ \\
\hline STZ+LMT125 & $198.23 \pm 4.23$ & $125,34 \pm 5.46$ & $45.23 \pm 2.45$ & $39.50 \pm 2.72^{*}$ & $1.75 \pm 0.05$ \\
\hline
\end{tabular}

Table 2: * and\# are significant levels of difference at $\mathrm{p}<0.05$ relative to control and STZ only respectively.

STZ-only group showed significantly higher $(\mathrm{p}<0.05)$ TC compared to other groups. TG level is significantly higher $(\mathrm{p}<0.05)$ in STZ-only group compared to GL, LML and LMT treated groups. LML treated groups showed significantly higher HDL compared to other groups other treatment groups. LDL is significantly higher $(\mathrm{p}<0.05)$ in $\mathrm{STZ}$ only group 3.3 ORGAN WEIGHT compared to all treatment groups. STZ-only group showed significantly higher $(\mathrm{P}<0.05)$ AI compared to all treatment groups. STZ+LMT500 treated group showed significantly lower $(\mathrm{p}<0.05)$ AI than all other groups. 

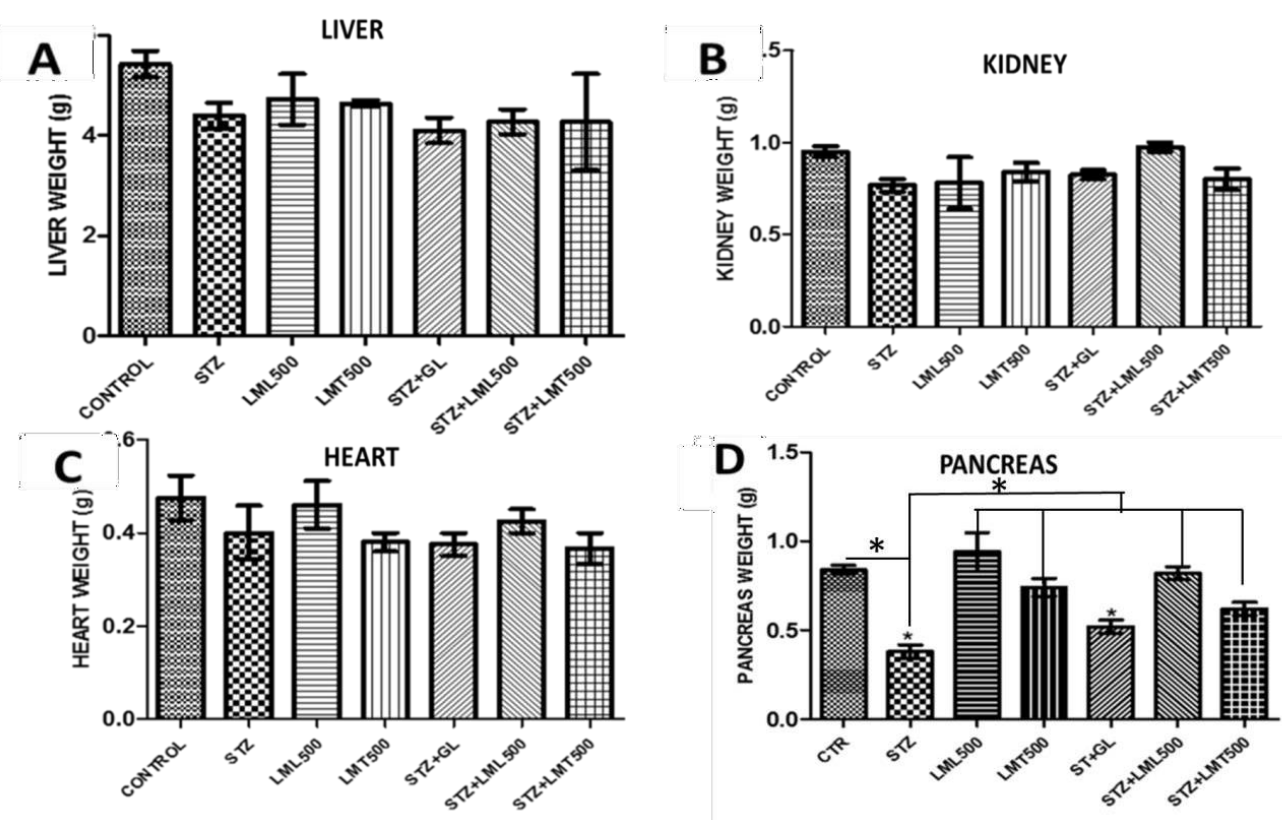

FIGURE 4: Graph A, B, C and D showing the weight of liver, kidney, heart and pancreas of experimental animals respectively. There was no significant difference in weight of liver, kidney and heart across the experimental groups. However, weight of pancreas in STZ-only, and STZ+GL groups showed significant reduction $(\mathrm{p}<0.05)$ compared to other groups.

$\mathrm{CTR}=$ control, $\mathrm{LML}=$ L. micranthus leaf extract, $\mathrm{LMT}=$ L. micranthus twig extract, $\mathrm{STZ}=$ streptozotocin, $\mathrm{GL}=$ glibenclamide.

* and \# are p value $>0.05$ relative to control. Data is presented as mean (bars) \pm standard error of mean (error bars).

\subsection{Histopathological Observations}

Following tissue microscopic examination, pancreatic tissues from all animals were evaluated and it was observed that the control group pancreas showed normal architecture, with intact acinar cell cytoplasmic and nuclear structures. In rats administered $65 \mathrm{mg} / \mathrm{kg}$ body weight STZ to induce a diabetic state, it was observed that there was severe diffuse necrosis of both exocrine and endocrine pancreatic tissues. Although, the diabetic group treated with glibenclamide in a bid to reverse the destructive effect of Streptozocin treatment showed some multifocal

pancreatic necrosis, overall, the animals in this group showed severe acinar (exocrine) nuclei hyperchromasia, possibly an indication of increased acinar cells' nuclei activity. The pancreas of STZ induced diabetic rats treated with $L$. micranthus leaf extract showed mostly normal acinar cells (figure 1D). The pancreas of STZ induced diabetic rats treated with L. micranthus twig extract showed bridging pancreatic necrosis admixed normal acinar regions (figure 1E), implying normal pancreatic tissue admixed necrotic tissue. 

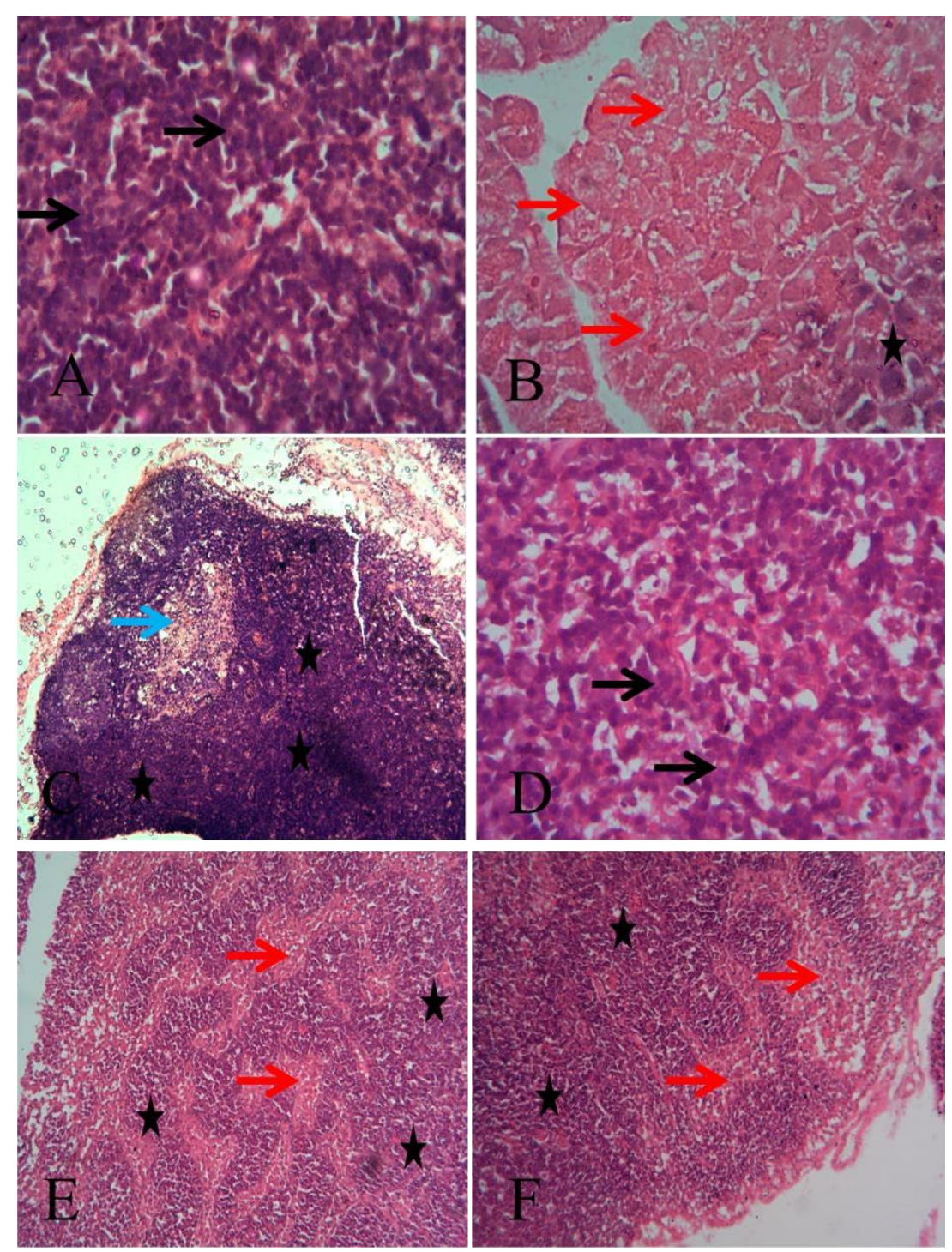

Figure 5: Representative photomicrograph of general morphology of the pancreas of experimental animals. A- control: normal acinar cells (black arrows) X40 HE; B- STZ-only: showing severe diffuse necrosis (red arrows) X40 HE; C: STZ-GL-treated: showing severe acinar cells hyperchromasia (black arrows) and normal islet (light blue arrow) X40 HE, D:STZ-LML-500 treated: showing mostly normal acinar cells(black arrows) X40 HE; E:STZ-LMT-500 treated: showing bridging pancreatic necrosis (red arrows)admixed normal acinar regions (black stars)X10 HE; F (higher magnification of E); Pancreas (DT), streptozocin induced diabetes and L. micranthus twig treatment X40 HE.

\section{DISCUSSION}

Diabetes mellitus (DM) is a serious chronic disease, with heavy cost implication on human population globally [8]. This has heightened the search for alternative therapies with potentially low toxicity, and hence better safety profile, for the treatment of the disease, to improve the quality of life of diabetic patients, and/ or reverse diabetic complications.

Gas chromatography - mass spectrophotometric (GC-MS) analysis showed the presence of different compounds in the twig and leaf extract at varying concentrations. This suggests that the presence of these compounds could be contributory to their unique antidiabetic activity. Leaf extract showed the presence of higher concentration of palmitic methyl ester which has been reported to possess several antidiabetic properties including activation of peroxisome proliferator-activated receptor (PPAR) family [31] and inhibition of $\alpha$-amylase and $\alpha$ glucosidase [32]. Other components such as Thymol, linmonene, 
camphor, and benzoic acid derivatives, have shown good antioxidant and antidiabetic potentials $[33,34,35]$. Thirteen compounds were found to be common in both leaf and twig extract of L. micranthus.

Acute toxicity study of both the leaf and the twig extract showed that both were safe at the maximum concentration $(2000 \mathrm{mg} / \mathrm{kg}$ body weight) employed. This finding supports previous safety study on L. micranthus [36]. This showed that the methanolic extracts of the both leaf and twig of $L$. micranthus are safe at the doses administered to the animals.

One of the mechanisms of action of antidiabetic agents include: causing reduction in glucose absorption from the gastrointestinal tract (GIT) [37]. This was assessed by evaluating the in vitro inhibitory effect of LML and LMT on starch degrading enzymes ( $\alpha$-amylase and $\alpha$-glucosidase). Clinically used antidiabetic drugs, such as Acarbose and miglitol inhibit both enzymes and reduce the rate of digestion of complex carbohydrates but this is accompanied by gastrointestinal discomforts [38]. Management of blood glucose level is a critical strategy in the control of diabetes and its complications, this makes leaf and twig extracts of L. micranthus potential candidates for controlling glucose release at GIT level. Both extracts could prevent postprandial spikes that have been implicated in cardiovascular and macro-vascular complications of diabetes[39].The twig extract showed better inhibitory effect on $\alpha$-amylase and $\alpha$ glucosidase compared to the leaf extract.

STZ-induced hyperglycemia was established in all diabetic groups in order to evaluate the effect of LMT and LML on treatment groups. The significant weight loss $(\mathrm{p}<0.05)$ in all STZ-induced diabetic groups could be strongly linked to STZ-induced destruction of beta cells of the islets of langerhans of the pancreas; the attending abolition of insulin production and secretion, and resultant decreased glucose uptake and storage [40,41]. The destruction of the pancreas resulted in utilization of noncarbohydrates nutrients such as proteins and fatty acid for the synthesis of glucose. The loss of structural proteins as a result of increased gluconeogenesis together with increased glycolysis and increased synthesis of ketone bodies results in severe weight loss in diabetic animals [40, 41]. L. micranthus extracts- and- glibenclamide treated groups showed similar weight gain pattern which is indicative of the ameliorating effect of the treatments on weight loss in STZ-induced diabetic rats. The effects of the extracts in ameliorating STZ-induced weight loss has been reported for borneol, cavarcol and Swertianmarine [42,43,44]. Twig and leaf extract of $L$. micranthus may contain principles useful in ameliorating weight loss seen in Type-1 DM.

Persistent hyperglycemia is a major factor in the pathophysiology of DM. Hypoglycemic agents should possess the ability to reduce the fasting blood glucose in diabetic patients. From the presents study, the fasting blood glucose of all animals in different groups at the start of the experiment were not significantly different $(\mathrm{p}>0.05)$. After induction of diabetes, the diabetic groups showed significant hyperglycemia which could be attributed to destruction of pancreatic beta cells, causing reduction in insulin production and hence, poor glucose utilization. The result showed adequate control of hyperglycemia in the glibenclamidetreated group and the L. micranthus leaf and twig-extract treated groups. The hypoglycemic effect of the extracts was observed at day 7 of treatment, and was consistent up to day 14 of treatment, suggesting that the extracts could be used for management of DM-induced hyperglycemia. This is consistent with the previous studies in alloxaninduced diabetes $[45,46]$.

The effect of glibenclamide, LML and LMT on glucose utilization assessed by the oral glucose tolerance test (OGTT) exhibited comparable glucose utilization pattern to normoglycemic group. This showed that both leaf and twig extracts of $L$. micranthus had similar effect on glucose utilization comparable to glibenclamide $(\mathrm{p}<0.05)$.

DM impairs glycogen synthesis both in the rat's liver and skeletal muscles [47]. The glycogen content of skeletal muscle and liver are markedly decreased in DM [48]. Result of the present study showed increase in the liver glycogen content of all extract-treated animals compared to the diabetic untreated group. LMT treated animal showed significantly $(\mathrm{p}<0.05)$ higher liver glycogen levels compared to other groups. Normal control group, LML500 and STZ-LML500 groups showed similar liver glycogen levels. This showed that the leaf and twig extracts of $L$. micranthus could improve glycogen storage possibly by inducing glycogenesis or reducing glycogenolysis in DM. This activity has been reported for borneol, citornellol and mytenal $[42,49,50,51]$ which were monoterpenes derived from different plants with antidiabetic activities.

The damaging effect of streptozotocin on pancreatic beta cells resulted in reduction in the level of serum insulin of the diabetic untreated rats compared to the control, glibenclamide-treated and L. micranthus extracttreated diabetic rats. LML500 treated diabetic rats showed higher serum insulin level than glibenclamide (an insulin secretagogue. [52] and LMT 500. Thus suggesting that leaf extract of L. micranthus has better insulinsecreting activity than the twig and glibenclamide-treated group. The result correlate with the findings of Gray and Flatt [53]

LML500 and LMT500 extracts had significantly higher $(\mathrm{p}<0.05)$ effect at reducing haemoglobin glycation comparable to glibenclamide. Clinical studies have shown that glycated hemoglobin is higher in diabetic patients than in non-diabetic individuals [54]. In the present study, reduction in haemoglobin glycation by the extracts could also be attributed to the activity in stimulating insulin secretion, or increasing glycogenesis and glucose utilization, leading to reduced blood glucose level and reduction in the rate of haemoglobin glycation. In addition, the antioxidant effect on phytochemicals in L. micranthus extracts similar to what was reported for D-limonene and thymol in previous studies $[55,56]$ could play a role.

The role of tumor necrotic factor- $\alpha$ (TNF- $\alpha)$, an adipocytokine in systemic inflammation has been established in DM [57,58]. LML500 and LMT500-treated diabetic group showed a significantly lower $(\mathrm{p}<0.05)$ TNF- $\alpha$ level compared to all other groups. Results from the present study also showed that $L$. micranthus leaf extract exhibited better serum TNF$\alpha$ lowering effect than glibenclamide. The leaf and twig extracts of $L$. micranthus may reduce diabetic complications by exerting antiinflammatory activity and lowering levels of TNF- $\alpha$ in inflammatory and metabolic diseases such as DM. Similar effect has been reported in adipocytes for geniposide [59].

Dyslipidemia is a critical feature of uncontrolled DM, characterized by high total cholesterol (TC), low density lipoprotein (LDL) cholesterol and triglycerides, and a reduction in the level of high density lipoprotein (HDL) cholesterol [14]. Acute insulin deficiency initially causes an increase in free fatty acid mobilization from adipose tissue resulting in an increased production of LDL cholesterol particles and resultant dyslipidemia [60, 61, 62]. LML500 and LMT500 showed similar control of the TC, LDL and serum triglyceride level at all doses used. Similarly, hypercholesterolemia observed in diabetic-untreated groupwere lowered in glibenclamide, LML and LMT treated groups. In addition, HDL cholesterol level was significantly increased $(p<0.05)$ in extract-treated animals than glibenclamide-treated group. Thus, suggesting a role for the extracts in the management of diabetic-induced dyslipidemia. Similar effect has been reported for D-Limonene and thymol $[44,55]$ 
Atherogenic index is a predictor of atherosclerosis, resulting from the imbalance between HDL and total cholesterol. Atherosclerosis is a major contributor to the global morbidity and mortality, both in hypertensive and diabetic individuals [63, 64]. LML-treated groups showed atherogenic index significantly lower $(\mathrm{p}<0.05)$ than the glibenclamide treated group. The extracts showed potent antidyslipidemic effect. The extracts may therefore be useful at reducing the risk of cardiovascular, and vascular events and death that are complications of chronic DM.

Analysis of weight of organs showed no significant difference $(p>0.05)$ in the weight of the liver, heart and kidney of all experimental groups. Weight of pancreas for the STZ-diabetic untreated group was significantly lower $(p<0.05)$ compared to weights of the pancreas in all other experimental groups. The increase in the weight of pancreas of LML500 treated group suggests that LML contain active phytochemicals that are capable of regenerating pancreatic beta cells. Further studies are required to confirm this finding.

The histopathological photomicrograph of the pancreas of experimental animals in this study re-enforces the destructive nature of STZ on both exocrine and endocrine pancreatic tissues, as it caused necrosis in these tissues. Also, the efficacy of glibenclamide in the treatment/management of diabetic state was shown to be partly due to increased activity of the islet and acinar cells which in the present study were observed to be hyperchromatic. This study demonstrates the ameliorating effect of $L$. micranthus leaf and twig extracts on the STZ- induced destruction of acinar and beta cells of the pancreas. Similar effects has been reported for menthol and palmitic acid ester [31, 51, 65].

In conclusion, this study showed the therapeutic benefits of $L$. micranthus in management of, and prevention of complications of DM via different mechanisms. Further studies are required to identify the phytochemical principles responsible for these antidiabetic actions and their possible mechanisms of action tested.

\section{Acknowledgement}

We acknowledge the staff of Central Research Laboratory, Animal House and Chemical Engineering Department, University of Ilorin, Ilorin for their contributions to this work. We also acknowledge Mr Femi Adesua of Department of Pharmacology and Therapeutics, University of Ilorin, Ilorin for his contributions in the extract preparation.

\section{Conflict of Interest}

The authors of this manuscript declare that there is no conflict of interest

\section{Funding}

This research did not receive any specific grant from funding agencies in the public, commercial, or

Not-for-profit sectors.

\section{References}

1. Mahato R V, Gyawali P, Raut P P, Regmi P, Singh K P et al (2011). Association between glycaemic control and serum lipid profile in type 2 diabetic patients: Glycated haemoglobin as a dual biomarker. Biomed Res, 22(3):375-380.

2. "About diabetes". World Health Organization. Retrieved 4 April 2018.
3. Clark N G, Fox K M, Grandy S. (2007). Symptoms of diabetes and their association with the risk and presence of diabetes. Diabetes Care; 30(11):2868-2873.

4. Rabbani N, Godfrey L, Xue M, Shaheen F, Geoffroin M, et al (2011). Glycation of LDL by Methylglyoxal Increases Arterial Atherogenicity A Possible contributor to Increased Risk of Cardiovascular Disease in Diabetes. Diabetes, 60(7);1973-1980.

5. Cho N.H, Shaw J.E, Karuranga S, Huang Y, da Rocha Fernandes J.D, et al (2018). IDF Diabetes Atlas: Global estimates of diabetes prevalence for 2017 and projections for 2045. Diabetes Res \& Clin. Prac. 138; 271-281.

6. IDF Diabetes Atlas Group. (2013) Update of mortality attributable todiabetes for the IDF Diabetes Atlas: estimates for the year2011. Diabetes Res Clin Pract;100(2) :277-279.

7. Roglic G, Unwin N. (2010) Mortality attributable to diabetes: estimates for the year 2010. Diabetes Res Clin Pract;87(1): 15-9.

8. Da Rocha Fernandes J, Ogurtsova K, Linnenkamp U, Guariguata L, Seuring T, et al (2016). IDF diabetes atlas estimates of 2014 global health expenditures on diabetes. Diabetes Res Clin Pract; $117: 48-54$.

9. Brucalla A and Cerami A. (1992). Advanced glycosylation: Chemitry, Biology and Implications for Diabetes and aging. Adv. Pharmacol. 23: 1-34.

10. Buciarelli. A, Wendt T and Qu W. (2002). Rage Blocade Stabilize established artherosclerosis in diabetic apolipoprotein E-Null mice. Circulation. 106:2827-2835

11. Melpomeni P. (2003). Glucose, Advanced Glycated End Products, and diabetic complications: What is new and What Works. Clinical Diabetes. 21(4):148-149.

12. Naka Y, Buciarelli LG and Went T. (2004). RAGE Axis. Animal Model and Novel insights into vascular complications of Diabetes. Arterioster. Vasc Biol. 24:1342-1349.

13. Vlassara H. (2005). Advanced Glycation in Health and Disease: Role of Modern Environment. Annals of New York Academy of Science. 1043:452-460.

14. Manjunath CN, Rawal JR, Irani PM, Madhu K. (2013) Atherogenic dyslipidemia. Indian J EndocrMetab. 17(6):969-976.

15. Donath, M.Y. and Shoelson, S.E. (2011) Type 2 Diabetes as an Inflammatory Disease. Nature Reviews Immunology, 11, 98-107.

16. Lontchi-Yimagou E, Sobnqwi E, Matsha T.E, and Kengne A.P (2013). Diabetes mellitus and inflammation; Curr Diab Rep. 13(3)435-444.

17. Adeneye A.A, Amole O.O. and Adeneye A.K.(2006a). Hypoglycemic and hypocholesterolemic activities of the aqueous leaf and seed extract of Phyllanthus amarus in mice. Fitoterapia, 77: 511-514.

18. Griggs P. (1991)"Mistletoe, myth, magic and medicine," The Biochemist, 13; 3-4.

19. Osadebe PO, Okide GB, Akabogu IC (2004). Study on the antidiabetic activity of crude methanolic extracts of Loranthus micranthus (Linn.) sourced from five different host trees. J Ethnopharmacol ,95:133-138.

20. Nwaegurue E, Nweke IN, Ezeala C. C, Nnekwe PC. (2007) Glucose lowering effects of Viscus album in normal and diabetic rats. J Res in Med Sci, 12(5):235-240.

21. Brown D. (1995).Encyclopedia of herbs and their uses. London: Dorling Kindersley.

22. Osadebe PO, Omeje EO, Uzor PF, David EK, Obiorah DC. (2010) Seasonal variation for the antidiabetic activity of Loranthus 
micranthus methanol extract. Asian Pacific Journal of Tropical Medicine. 3(3):196-199.

23. Jennings, W and Shibamoto T(1980). Qualitative analysis of flavor and fragrance volatiles by glass capillary gas chromatography, Academic Press, New York.

24. Joulain, D. and Koenig, W.A. (1998) The Atlas of Spectral Data of Sesquiterpene Hydrocarbons. E. B. Verlag, Hamburg.

24. Lenzen, S. (2008). The mechanisms of alloxan- and streptozotocininduced diabetes. Diabetologia. 51(2): 216-226.

25. Ayala, J.E, Samuel, V.T, Morton, G.J, Obisi, S, Croniger, C.M, (2010). Standard operating procedures for describing and performing metabolic tests of glucose homeostasis in mice. Dis. Model Mech. 3(9-10): 525-534.

26. Ali, H, Houghton, PJ, Soumyanath, A. (2000). $\alpha$-Amylase inhibitory activity of some Malaysian plants used to treat diabetes; with particular reference to Phyllanthus amarus. Journal of Ethnopharmacology; 107(3): 449-455.

27. Kim, Y.M, Jeong, Y.K, Wang, M.H, Lee, W.Y, and Rhee, H.I. (2005). Inhibitory effect of pine extract on $\alpha$-glucosidase activity and postprandial hyperglycemia. Nutrition; 21(6): 756-761.

28. Friedewald, WT, Levy RI, Fredrickson DS. (1972). Estimation of the concentration of low-density lipoprotein cholesterol in plasma without use of the preparative ultracentrifuge. Clin. Chem; 18: 499502.

29. Harnafi H, Caid HS, Bouanani NH, Aziz M, Amrani S. (2008). Hypolipidemic activity of polyphenol-rich extracts from Ocimum basilicum in triton WR-1339-induced hyperlipidemic mice. Food Chem; 108(1): 205-212.

30. Jian-Hong Lin and Kun-Ta Yang. (2017). Palmitic Acid Methyl Ester Regulates Proliferation of Human Mesenchymal Stem Cells. The FASEB Journal. Vol. 31(1).

31. Atolani, O, Adeniyi, O, Kayode, O.O. and Adeosun, C.B. (2015). Direct Preparation of Fatty Acid Methyl Esters and Determination of in Vitro Antioxidant Potential of Lipid from Fresh Sebal causarium Seed. Journal Applied Pharmaceutical Science. 5; 2428. [16]

32. Saravanan, S. and Pari, L. (2015) Role of Thymol on Hyperglycemia and Hyperlipi-demia in High Fat Diet-Induced Type 2 Diabetic C57BL/6J Mice: Review. European Journal of Pharmacology, 76, 279-287.

33. Rangasamy, K. and Namasivayam, E. (2014) In Vitro Antioxidant and Free Radical Scavenging Activity of Isolongifolene. Asian Journal of Biological Science, 5; 1-11.

34. Ezuruike, U.F. and Prieto, J.M. (2014) Review: The Use of Plants in the Traditional Management of Diabetes in Nigeria: Pharmacological and Toxicological Considera-tions. Journal of Ethnopharmacology, 155; 857-924.

35. Moghadamtousi,S.Z, Hajrezaei M, Kadir H.A and Zandi K. (2013). Loranthus micranthus Linn.: BiologicalActivities and Phytochemistry. Evidence-Based Complementary and Alternative Medicine, Article ID 273712, 9 pages.

36. Scheen, A J. (1998). "Clinical efficacy of acarbose in diabetes mellitus: a critical review of controlled trials". Diabetes Metab. 24 (4): 311-320.

37. Fujisawa T, Ikegami H, Inoue K, Kawabata Y, Ogihara T. (2005). Effect of two alpha-glucosidase inhibitors, voglibose and acarbose, on postprandial hyperglycemia correlates with subjective abdominal symptoms. Metabolism. 54:387-390

38. Kwon O, Eck, P, Chen, S, Corpe CP, Lee JH et al., 2007. Inhibition of the intestinal glucose transporter GLUT2 by flavonoids. FASEB Journal; 21(2): 366-377.

39. Andulla B, Varadacharyulu NCH.( 2003) Antioxidant role of mulberry leaves in streptozotocin-diabetic rats. Clin Chim Acta.;338:3-10.

40. Yanardag R, Ozsoy-Sacan O, Bolkent S,Orak H, Karabulut-Bulan $\mathrm{O}(2005)$. Protective effects of metformin treatment on the liver injury of the streptozotocin-diabetic rats. Hum Exp Toxical.;24:129-135.

41. Kodikonda M., Naik P.R. (2017).Ameliorative effect of borneol, a natural bycyclic monoterpene against hyperglycemia, hyperlipidemia and oxidative stress in streptozotocin-induced diabetic Wistar rats. Biomed. Pharmacother.;96:336-347.

42. Ezhumalai M, Ashokkumar N, Pugalendi K.V (2015). Combination of carvacrol and rosiglitazone ameliorates high fat diet induced changes in lipids and inflammatory markers in C57BL/6J mice. Biochimie.;110:129-136.

43. Vaidya H., Prajapati A., Rajani M., Sudarsanam V., Padh H,et al (2012).Beneficial Effects of Swertiamarin on dyslipidaemia in streptozotocin-induced Type 2 diabetic rats. Phytother. Res;26:1259-1261.

44. Adeeyo AO, Adefule AK, Ofusori DA, Aderinola AA, CaxtonMartins EA. (2013). Antihyperglycemic effects of aqueous leaf extracts of mistletoe and Moringa oleifera in Streptozotocininduced diabetes Wistar rats. Diabetologia Croatia; 42-43.

45. Osadebe PO, Omeje EO, Uzor PF, David EK, Obiorah DC. (2010). Seasonal variation for the antidiabetic activity of Loranthusmicranthus methanol extract. Asian Pacific Journal of Tropical Medicine. 3(3):196-199.

46. Hwang DF, Lai YS, Chiang MT. (1996). Toxic effects of grass carp, snake and chicken bile juices in rats. ToxicolLett; 85(2): 8592.

47. Abdel-Sattar EA, Elberry AA, Harraz FM, Ghareib SA, Nagy AA (2011). Antihyperglycemic effects of the methanolic extract of Saudi mistletoe (Viscumschimperi Engl.). Journal of $A d v$. Research; 2: 171-177.

48. Srinivasan S., Muruganathan U. (2016). Antidiabetic efficacy of citronellol, a citrus monoterpene by ameliorating the hepatic key enzymes of carbohydrate metabolism in streptozotocin-induced diabetic rats. Chem. Biol. Interact.;250:38-46.

49. Rathinam A, Pari L. (2016) Myrtenal ameliorates hyperglycemia by enhancing GLUT2 through Akt in the skeletal muscle and liver of diabetic rats. Chem. Biol. Interact.;256:161-166.

50. Rathinam A, Pari L, Chandramohan R, Sheikh B.A(2014). Histopathological findings of the pancreas, liver, and carbohydrate metabolizing enzymes in STZ-induced diabetic rats improved by administration of myrtenal. J. Physiol. Biochem.;70:935-946.

51. Luzi, L and Pozza G. (1997). Glibenclamide an old drug with a novel mechanism of action? Acta Diabetol, 34(4); 239-244.

52. Gray AM and Flatt PR. (1999). Insulin-secreting activity of the traditional antidiabetic plant Viscum album (mistletoe). $J$. Endocrinol., 160(3): 409-414.

53. Lester E. (1989). The clinical value of glycated hemoglobin and plasma protein. Ann clin. Biochem. 26: 213-219. 
54. Bacanlı M, Anlar H.G, Aydın S, Çal T, Arı N et al (2017). dlimonene ameliorates diabetes and its complications in streptozotocin-induced diabetic rats. Food Chem. Toxicol.;110:434-442.

55. Saravanan S, Pari L.(2016) Protective effect of thymol on high fat diet induced diabetic nephropathy in C57BL/6J mice. Chem. Biol. Interact $; 245: 1-11$.

56. Moller D.E. (2000). Potential role of TNF alpha in the pathogenesis of insulin resistance and type 2 diabetes. Trends Endocrinol Metab.11:212-217.

57. Zou C, Shao J. (2008). Role of adipocytokines in obesityassociated insulin resistance. J Nutr Biochem. 19:277-286.

58. Liu J, Yin F, Xiao H, Guo L, Gao X. (2012). Glucagon-like peptide 1 receptor plays an essential role in geniposide attenuating lipotoxicity-induced $\beta$-cell apoptosis. Toxicol. In Vitro.;26:10931097.

59. Arvind k,Pradeepa R, Deepa R, Mohan V(2002). "Diabetes and Coronary artery Disease. Indian J Med Res. 116:163-176.
60. Palumboa P.J. (1998). "Metformin: Effects on Cardiovascular risk factors in patients with non-insulin-dependent diabetes mellitus. $J$ Diabetes Complications. 12 (2):110-119.

61. Murali B., Upadhyaya U.M, Goyal R.K (2002). "Effect of Chronic treatment with Enicostemmalittorale in non-insulin dependent Diabetes Mellitus (NIDDM) rats. Journal of Ethnopharmacology; 81 (2): 199-204.

62. Libby P.( 2002). Inflammation in atherosclerosis. Nature; 420: 868-874.

63. Ikeda U. (2003) Inflammation and coronary artery disease. CurrVasc Pharmacol. 1: 65-70.

64. Muruganathan U, Srinivasan S, Vinothkumar V (2017). Antidiabetogenic efficiency of menthol, improves glucose homeostasis and attenuates pancreatic $\beta$-cell apoptosis in streptozotocin-nicotinamide induced experimental rats through ameliorating glucose metabolic enzymes. Biomed Pharmacother; 92:229-239 